\title{
Structure of Malonylshisonin, a Genuine Pigment in Purple Leaves of Perilla ocimoides L. var. crispa Benth
}

\author{
Tadao Kondo, ${ }^{*}$ Hirotoshi Tamura, ${ }^{* *}$ Kumi Yoshida*** \\ and Toshio Goto** \\ *Chemical Instrument Center, Nagoya University, \\ Chikusa, Nagoya 464, Japan \\ ** Laboratory of Organic Chemistry, Faculty of Agriculture, \\ Nagoya University, Chikusa, Nagoya 464, Japan \\ *** Laboratory of Food Hygiene, Faculty of Home Economics, \\ Sugiyamajogakuen University, Chikusa, \\ Nagoya 464, Japan \\ Received October 19, 1988
}

\begin{abstract}
The structure of malonylshisonin, a genuine pigment in purple Perilla leaves, was determined to be 3-O-(6-O-(E)-p-coumaryl- $\beta$-D-glucopyranosyl)-5- $O$-(6-O-malonyl- $\beta$-D-glucopyranosyl)cyanidin.
\end{abstract}

Purple leaves of Perilla ocimoides (Japanese name shiso) are widely used for coloring traditional Japanese plum pickles. In 1935, Kuroda isolated from the purple leaves a pigment and named it shisonin. ${ }^{1)}$ About 30 years later, Takeda and Hayashi, ${ }^{2)}$ and Watanabe et al. ${ }^{3)}$ determined its structure to be cyanidin 3-(6p-coumaryl-D-glucosido)-5-glucoside, whose complete structure was established by us. ${ }^{4} \mathrm{We}$ have recently reported that shisonin is actually an artifact; the genuine anthocyanin ${ }^{5)}$ is a malonylated shisonin named malonylshisonin, whose complete structure and stereochemistry is 3-O-(6-O- $(E)$ - $p$-coumaryl- $\beta$-D-glucopyranosyl)-5-O-(6-O-malonyl- $\beta$-D-glucopyranosyl)cyanidin. Takeda et al. ${ }^{6)}$ also assumed it to be malonylated shisonin from its FABMS analysis. This paper is a detailed report on the isolation and structural determination of malonylshisonin.

Fresh leaves of Perilla ocimoides were extracted with $3 \%$ aqueous trifluoroacetic acid (TFA), chromatographed on an Amberlite XAD-7 column and purified by means of a preparative ODS-HPLC to give a pigment, malonylshisonin (1), as a dark red amorphous TFA salt.

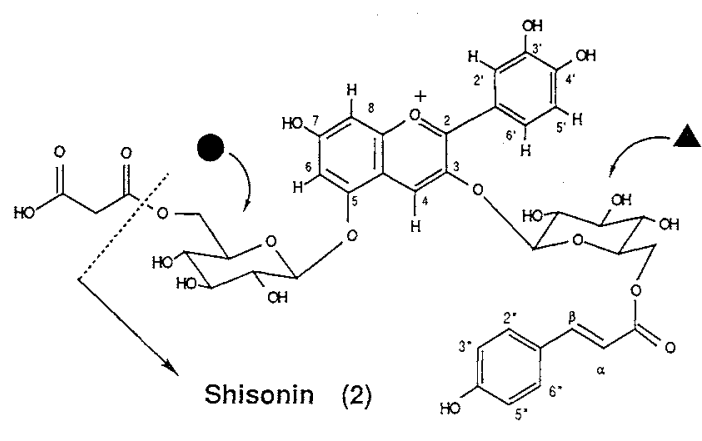

Malonylshisonin (1)

By acid hydrolysis, 1 was converted to shisonin (2). FABMS of $\mathbf{2}$ gave its molecular peak at $m / z 757$. Its ${ }^{1} \mathrm{H}$ NMR spectrum $(500 \mathrm{MHz})$ showed the presence of a cyanidin nucleus, a (E)-p-coumaryl moiety $\left(J_{\alpha, \beta}=16 \mathrm{~Hz}\right)$ and two hexopyranosides, in which all of the vicinal methine coupling constants were $7.5 \sim 9.0 \mathrm{~Hz}$, indicating that both of the hexosides were $\beta$-Dglucopyranosides. The position of attachment of the sugars to the anthocyanidin nucleus was shown by means of low-temperature NOE difference spectra. Irradiation of the anomeric protons, $\boldsymbol{\Delta}-1(5.49 \mathrm{ppm})$ and -1 $(5.21 \mathrm{ppm})$, at $-20^{\circ} \mathrm{C}$ in $\mathrm{CD}_{3} \mathrm{OD}$ containing 


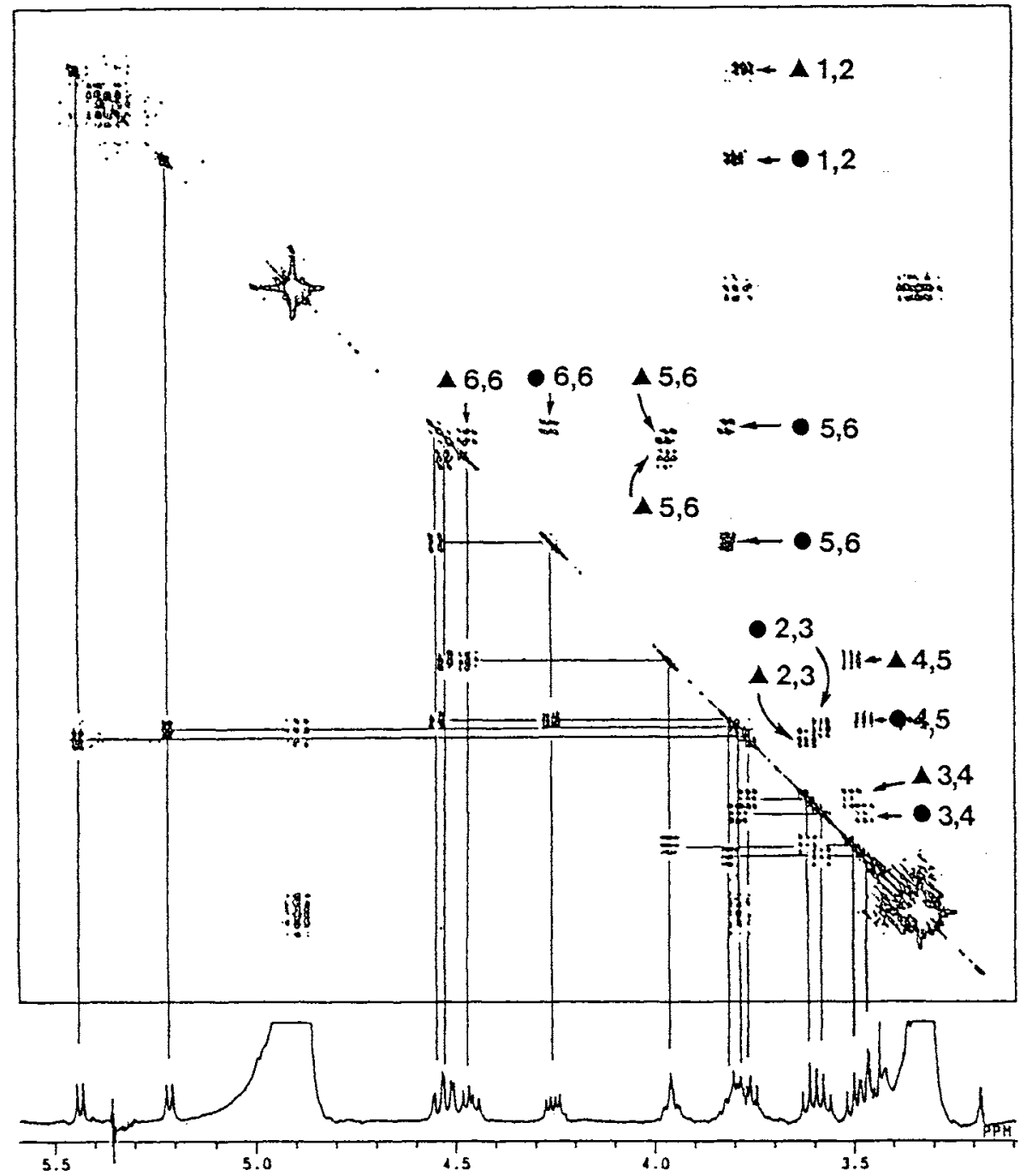

Fig. 1. ${ }^{1} \mathrm{H}-{ }^{1} \mathrm{H}$ COSY Spectrum of the Sugar Moieties of 1 in $3 \%$ TFA-d $-\mathrm{CD}_{3} \mathrm{OD}$ at $25^{\circ} \mathrm{C}$.

$3 \%$ TFA- $d$ decreased the intensity of the peaks of $\mathrm{H}-4(-11 \%)$ and $\mathrm{H}-6(-6 \%)$, respectively, indicating that the $\mathbf{\Delta}$ - and $\boldsymbol{0}$-glucose moieties were attached at the 3 and 5 positions of the cyanidin nucleus, respectively. ${ }^{7)}$ The assignments of all protons of the sugar moieties were made by ${ }^{1} \mathrm{H}-{ }^{1} \mathrm{H}$ spin decoupling experiments. The methylene protons of $\mathbf{\Delta}$-glucose appeared in about $0.5 \mathrm{ppm}$ lower field than that of glucose, indicating that the 6-position of $\boldsymbol{A}$ glucose was acylated. Thus, 2 must have been 3-O-(6-O- $(E)$ - $p$-coumaryl- $\beta$-D-glucopyranosyl)-5- $O$-( $\beta$-D-glucopyranosyl)cyanidin.
The FABMS of $1(m / z 843)$ suggested the existence of a malonyl group on $\mathbf{2}$, which was confirmed by the isolation of dimethyl malonate (38\% yield) from an acid methanolysis of 1 with $4 \%$ methanolic hydrochloric acid at $100^{\circ} \mathrm{C}$. All signals in the ${ }^{1} \mathrm{H}$ NMR spectrum of 1 could be assigned by means of ${ }^{1} \mathrm{H}-{ }^{1} \mathrm{H}$ COSY (Fig. 1) and low-temperature NOE difference experiments (Fig. 2). The methylene signals (4.54 and $4.23 \mathrm{ppm}$ ) of -glucose were shifted to lower fields than those of $\mathbf{2}$, indicating the attachment of the malonyl moiety at this position. Therefore, the structure of 1 was de- 


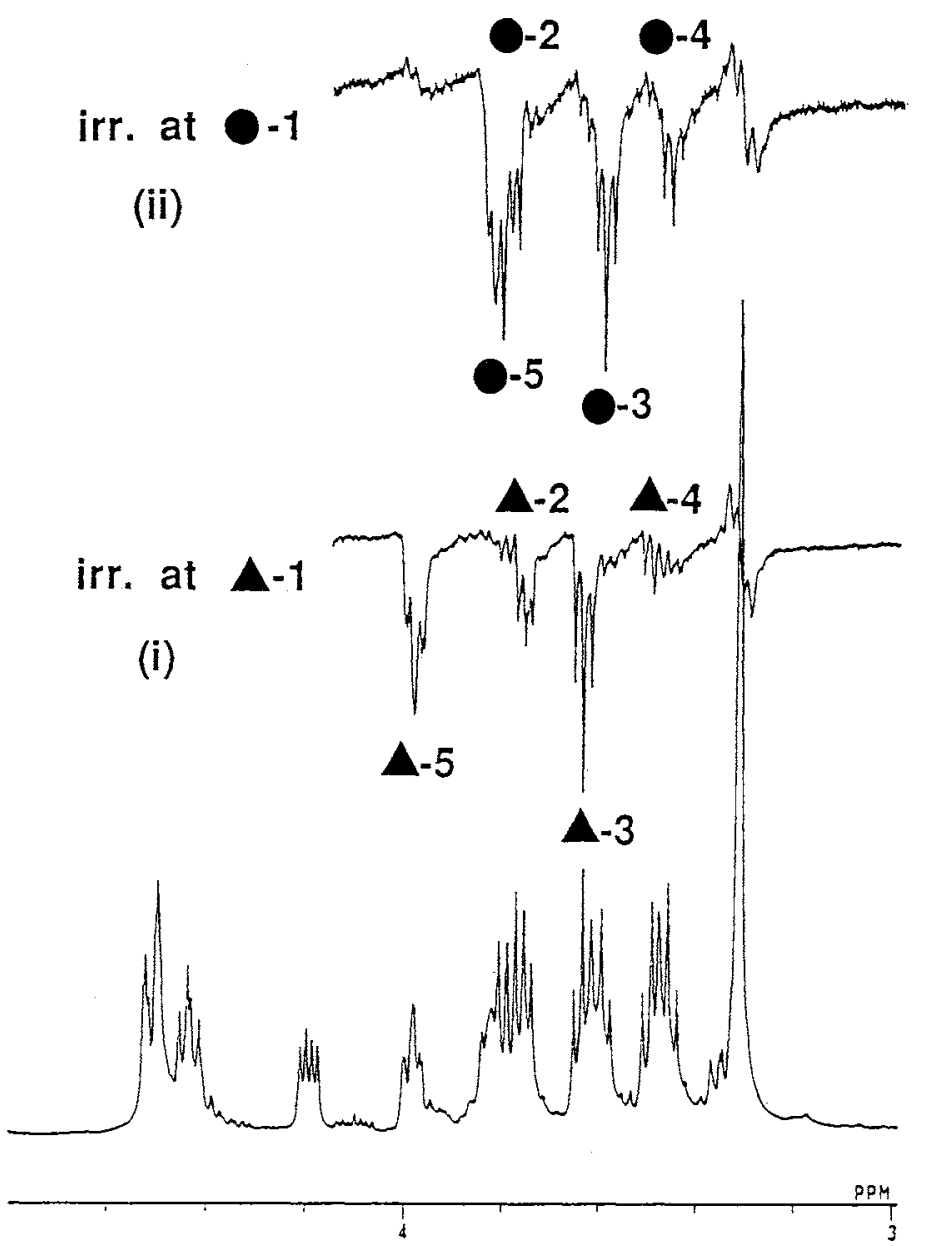

Fig. 2. NOE Difference Spectra of the Sugar Moieties of 1 at $0^{\circ} \mathrm{C}$, Irradiating at $\boldsymbol{\Delta}-1$ (i), and (ii).

termined as that shown before.

\section{Experimental}

General procedures. UV-VIS data were recorded on a Hitachi UV-228 spectrometer. ${ }^{1} \mathrm{H}$ NMR and ${ }^{1} \mathrm{H}^{-1} \mathrm{H}$ COSY spectra were obtained on a Brucker WM 360 and a JEOL GX500 spectrometer in a $5 \mathrm{~mm}$ tube at variable temperatures. Chemical shifts are reported as parts per million (ppm) downfield from internal tetramethylsilane (TMS) as a standard. FABMS data were recorded on a JEOL DX-300/DA5000 system, using a $1 \mathrm{~N} \mathrm{HCl-glycerol}$ matrix. For GC, a Shimadzu GC 9A equipped with a glass column and a FID detector was used. HPLC was carried out using a JASCO Trirotar III with a UVIDEC 100-III detector. Analytical HPLC was carried out by using an ODS-column (Develosil ODS-5, Nomura Chemical), which was eluted with a $40 \%$ A solution (diluted with
$\mathrm{H}_{2} \mathrm{O} ; \mathrm{A}$ was a mixture of $\mathrm{AcOH}-\mathrm{CH}_{3} \mathrm{CN}-\mathrm{H}_{2} \mathrm{O}=20$ : $25: 55)$ containing $3 \% \mathrm{H}_{3} \mathrm{PO}_{4}$. For preparative HPLC, an ODS glass column (Develosil ODS-lop) was used, which was eluted with a $35 \%$ A solution containing $3 \%$ TFA. For replacing $\mathrm{H}_{3} \mathrm{PO}_{4}$ with a volatile acid, the eluate was diluted by four times the volume of $\mathrm{H}_{2} \mathrm{O}$, absorbed on the ODS-column, and eluted with solution A containing $1 \%$ TFA.

Isolation of malonylshisonin (1). Fresh purple leaves (500g) of Perilla ocimoides were extracted three times with a $3 \%$ aqueous trifluoroacetic acid (TFA) solution $(500 \mathrm{ml})$ at ambient temperature. The combined red extract was filtered and poured into an Amberlite XAD-7 column, and the column was eluted stepwisely from $\mathrm{H}_{2} \mathrm{O}$ to $\mathrm{CH}_{3} \mathrm{CN}$ containing $1 \% \mathrm{TFA}$. The $20 \% \mathrm{CH}_{3} \mathrm{CN}$ fraction contained mainly a pigment, which was purified by preparative ODS$\mathrm{HPLC}$, using $\mathrm{AcOH}-\mathrm{CH}_{3} \mathrm{CN}-\mathrm{H}_{2} \mathrm{O}(7: 9: 84)$ containing $3 \% \mathrm{H}_{3} \mathrm{PO}_{4}$ as an eluate. After replacing the counter anion, 
the pure fraction was dried to give malonylshisonin (1) as a dark-red amorphous solid of the TFA salt (yield $650 \mathrm{mg}$ ); UV-VIS $\lambda_{\max }(0.01 \% \mathrm{HCl}-\mathrm{MeOH}) \mathrm{nm}(\varepsilon): 517(27,700)$, $315(17,000), 280(22,200) ; E_{315 \mathrm{~nm}} / E_{517 \mathrm{~nm}}=0.613 ;{ }^{1} \mathrm{H}$ NMR $\left(3 \%\right.$ TFA- $d$ in $\mathrm{CD}_{3} \mathrm{OD}$ at $\left.25^{\circ} \mathrm{C}\right) \delta: 8.89(1 \mathrm{H}, \mathrm{s}, \mathrm{H}-$ 4), $8.23(1 \mathrm{H}$, dd, $J=1.5$ and $9.5 \mathrm{~Hz}, \mathrm{H}-6), 7.98(1 \mathrm{H}, \mathrm{d}$, $\left.J=1.5 \mathrm{~Hz}, \mathrm{H}-2^{\prime}\right), 7.37(\mathrm{lH}, \mathrm{d}, J=16 \mathrm{~Hz}, \mathrm{H}-\beta), 7.21(2 \mathrm{H}, \mathrm{d}$, $J=8.5 \mathrm{~Hz}, \mathrm{H}-2^{\prime \prime}$ and $\left.6^{\prime \prime}\right), 6.99\left(1 \mathrm{H}, \mathrm{d}, J=8.5 \mathrm{~Hz}, \mathrm{H}-5^{\prime}\right)$, $6.98(1 \mathrm{H}, \mathrm{d}, J=1.8 \mathrm{~Hz}, \mathrm{H}-6), 6.92$ (1H, br. s, H-8), 6.71 $\left(2 \mathrm{H}, \mathrm{d}, J=8.5 \mathrm{~Hz}, \mathrm{H}-3^{\prime \prime}\right.$ and $\left.\mathrm{H}-5^{\prime \prime}\right), 6.24(1 \mathrm{H}, \mathrm{d}$, $J=16 \mathrm{~Hz}, \mathrm{H}-\alpha), 5.45(1 \mathrm{H}, \mathrm{d}, J=7.5 \mathrm{~Hz}, \mathbf{\Delta}-1), 5.19(1 \mathrm{H}, \mathrm{d}$, $J=7.5 \mathrm{~Hz},-1), 4.54(1 \mathrm{H}, \mathrm{dd}, J=2.5$ and $12 \mathrm{~Hz},-6 \mathrm{a})$, 4.52 ( $1 \mathrm{H}$, dd, $J=3.0$ and $12 \mathrm{~Hz}, \boldsymbol{\Delta}-6 \mathrm{a}), 4.43(1 \mathrm{H}, \mathrm{dd}, J=8$ and $12 \mathrm{~Hz}, \boldsymbol{\Delta}-6 \mathrm{~b}), 4.23(1 \mathrm{H}, \mathrm{dd}, J=6.5$ and $12 \mathrm{~Hz},-6 \mathrm{~b})$, $3.95(1 \mathrm{H}, \mathrm{ddd}, J=3,8$ and $9 \mathrm{~Hz}, \boldsymbol{\Delta}-5), 3.80(1 \mathrm{H}, \mathrm{ddd}$, $J=2.5,6.5$ and $9 \mathrm{~Hz},-5), 3.78(1 \mathrm{H}, \mathrm{dd}, J=7.5$ and $9 \mathrm{~Hz}$, -2), $3.76(1 \mathrm{H}$, dd, $J=7.5$ and $9 \mathrm{~Hz}, \boldsymbol{\Delta}-2), 3.62(1 \mathrm{H}, \mathrm{t}$, $J=9 \mathrm{~Hz}, \boldsymbol{\Delta}-3), 3.58(1 \mathrm{H}, \mathrm{t}, J=9 \mathrm{~Hz}, \boldsymbol{-}-3), 3.50(1 \mathrm{H}, \mathrm{t}$, $J=9 \mathrm{~Hz}, \boldsymbol{\Delta}-4), 3.46(1 \mathrm{H}, t, J=9 \mathrm{~Hz},-4)$; a negative NOE at $0 \% \mathrm{C}, \mathrm{H}-4$ (irrad.) $\rightarrow-\mathbf{A}-1 \quad(-14 \%), \mathrm{H}-6 \rightarrow-1$ $(-10 \%)$.

Analysis of malonic acid. $1(1.5 \mathrm{mg})$ was heated at $100^{\circ} \mathrm{C}$ in $4 \%$ methanolic $\mathrm{HCl}(1 \mathrm{ml})$ for $16 \mathrm{~min}$. The solution was diluted with ether, washed with $\mathrm{H}_{2} \mathrm{O}$, and evaporated to give dimethyl malonate in a $38 \%$ yield, which was identified by comparing with an authentic sample by $\mathrm{GC}$ analysis using a column $(1 \mathrm{~m})$ of $5 \%$ Carbowax $20 \mathrm{M}$ on Chromosorb $\mathrm{W}$ at $70^{\circ} \mathrm{C}\left(t_{\mathrm{R}} 8.8 \mathrm{~min}\right.$, the yield was calculated from the calibration curves).

Hydrolysis of 1 to shisonin (2). 1 (15.1 mg) was allowed to stand for $12 \mathrm{hr}$ in a $1 \% \mathrm{HCl}-\mathrm{MeOH}$ solution $(2 \mathrm{ml})$ at $40^{\circ} \mathrm{C}$, and the reaction mixture was condensed in vacuo. The residue was dissolved in $1 \%$ aq. TFA and the solution was charged to a preparative ODS column. Elution of the column with $35 \%$ A solution containing $3 \%$ TFA gave shisonin TFA salt (2) $(7.6 \mathrm{mg}, 55 \%$ yield) as a dark-red mass; UV-VIS $\hat{\lambda}_{\max }(0.01 \% \mathrm{HCl}-\mathrm{MeOH}) \mathrm{nm}$ (ह) 516 $(22,400), \quad 314(14,800), 279(19,700) ; E_{314 \mathrm{~nm}} / E_{516 \mathrm{~nm}}=$ $0.667 ;{ }^{1} \mathrm{H}$ NMR $\left(3 \%\right.$ TFA- $d$ in $\mathrm{CD}_{3} \mathrm{OD}$ at $\left.25^{\circ} \mathrm{C}\right) \delta: 8.94$ $(1 \mathrm{H}, \mathrm{s}, \mathrm{H}-4), 8.25(1 \mathrm{H}$, dd, $J=2.5$ and $8.5 \mathrm{~Hz}, \mathrm{H}-6), 8.00$ $\left(1 \mathrm{H}, \mathrm{d}, J=2.5 \mathrm{~Hz}, \mathrm{H}-2^{\prime}\right), 7.37(1 \mathrm{H}, \mathrm{d}, J=16 \mathrm{~Hz}, \mathrm{H}-\beta), 7.28$ $\left(2 \mathrm{H}, \mathrm{d}, J=8.5, \mathrm{H}-2^{\prime \prime}\right.$ and $\left.6^{\prime \prime}\right), 7.01(1 \mathrm{H}, \mathrm{d}, J=8.5 \mathrm{~Hz}, \mathrm{H}-$ 5), 7.00 (1 $\mathrm{H}$, br. s, H-6), 6.93 (1H, br.s, H-8), $6.76(2 \mathrm{H}, \mathrm{d}$, $J=8.5 \mathrm{~Hz}, \mathrm{H}-3^{\prime \prime}$ and $\left.5^{\prime \prime}\right), 6.22(1 \mathrm{H}, \mathrm{d}, J=16 \mathrm{~Hz}, \mathrm{H}-\alpha)$. $5.43(1 \mathrm{H}, \mathrm{d}, J=7.5 \mathrm{~Hz}, \boldsymbol{\Delta}-1), 5.17(1 \mathrm{H}, \mathrm{d}, J=7.5 \mathrm{~Hz}$, 1), $4.50(1 \mathrm{H}, \mathrm{dd}, J=3$ and $12 \mathrm{~Hz}, \mathbf{\Delta}-6 \mathrm{a}), 4.47(\mathbf{l H}$, dd, $J=6.5$ and $12 \mathrm{~Hz}, \boldsymbol{\Delta}-6 \mathrm{~b}), 3.98(\mathrm{H}, \mathrm{dd}, J=2$ and $12 \mathrm{~Hz}$, - $6 \mathrm{a}), 3.91$ ( $1 \mathrm{H}$, ddd, $J=3,6.5$, and $9 \mathrm{~Hz}, \boldsymbol{\Delta}-5), 3.76(1 \mathrm{H}$, $\mathrm{dd}, J=7.5$ and $9 \mathrm{~Hz}, \boldsymbol{\Delta}-2), 3.75(1 \mathrm{H}, J=7.5$ and $9 \mathrm{~Hz}$, $\mathbf{-}$ 2), $3.74(1 \mathrm{H}, \mathrm{dd}, J=6$ and $12 \mathrm{~Hz},-6 \mathrm{~b}), 3.62(1 \mathrm{H}$, ddd, $J=2,6$ and $9 \mathrm{~Hz},-5), 3.62(1 \mathrm{H}, \mathrm{t}, J=8.5 \mathrm{~Hz}, \boldsymbol{\Delta}-3), 3.58$ $(1 \mathrm{H}, \mathrm{t}, J=9 \mathrm{~Hz},-3), 3.53(\mathrm{l} \mathbf{H}, \mathrm{t}, J=9 \mathrm{~Hz}, \boldsymbol{\Delta}-4), 3.45$ $(1 \mathrm{H}, \mathrm{t}, J=9 \mathrm{~Hz}, \mathbf{-}-4)$.

Acknowledgments. We thank the Ministry of Education, Science and Culture, and the Fujisawa Foundation for financial support, and $\mathrm{Mr}$. H. Hattori of the National Institute for Basic Biology for a preliminary $360 \mathrm{MHz}{ }^{1} \mathrm{H}$ NMR measurement.

\section{References}

1) C. Kuroda and M. Wada, Proc. Imp. Acad. (Tokyo), 11, 28 (1935). See also K. Kondo, J. Pharm. Soc. Jpn., 51, 254 (1931).

2) K. Takeda and K. Hayashi, Proc. Jpn. Acad., 40, 510 (1964).

3) S. Watanabe, S. Sakamura and Y. Obata, Agric. Biol. Chem., 30, 420 (1966).

4) T. Goto, S. Takase and T. Kondo, Tetrahedron Lett., 1978, 2413.

5) T. Kondo, T. Tamura and T. Goto, Abstracts of Papers, Joint Meeting of the Kansai and Chubu Branches of the Agricultural Chemical Society Japan, Kobe, Oct. 1985, p. 20.

6) K. Takeda, J. B. Harborne and R. Self, Phytochemistry, 25, 2191 (1986).

7) T. Goto, T. Kondo, H. Tamura and S. Takase, Tetrahedron Lett., 24, 4863 (1983). 